\title{
Oxygen-deficient niches on the northern European epicontinental shelf across the Toarcian carbon isotope excursion interval
}

\author{
YUNFENG WANG ${ }^{1}$, FRANTZ OSSA OSSA ${ }^{2}$, JORGE E. \\ SPANGENBERG ${ }^{3}$, MARTIN WILLE ${ }^{4}$ AND RONNY \\ SCHOENBERG $^{5}$ \\ ${ }^{1}$ University of Tuebingen, Germany \\ ${ }^{2}$ University of Tuebingen \\ ${ }^{3}$ University of Lausanne \\ ${ }^{4}$ University of Bern \\ ${ }^{5}$ University of Johannesburg \\ Presenting Author: yunfeng.wang@uni-tuebingen.de
}

The worldwide recognition of the Toarcian carbon isotope excursion (T-CIE) in organic-rich sedimentary rocks has been linked to an oceanic anoxic event (OAE) that deoxygenated the world's deep oceans $\sim 183$ million years ago (Ma) [1]. The majority of independent redox proxies used to build this argument were mainly obtained from organic-rich T-CIE sedimentary rocks deposited in the northern European epicontinental shelf settings. However, increasing evidence has shown that European epicontinental sedimentary environments had limited connection with the open ocean [2], making these settings poor proxies for reconstructing the T-CIE ocean redox structure. To unveil the controversial oceanic redox structure during the T-CIE, this study presents integrated nitrogen isotope compositions of bulk rock and extracted kerogen (expressed as $\delta^{15} \mathrm{~N}_{\text {bulk }}$ and $\delta^{15} \mathrm{~N}_{\text {ker }}$, i.e., the per mil (\%o) difference in ${ }^{15} \mathrm{~N} /{ }^{14} \mathrm{~N}$ ratio relative to air- $\mathrm{N}_{2}$ standard) from the sedimentary succession of Dotternhausen, southwestern Germany, in combination with literature data from other recognized T-CIE profiles. Both $\delta^{15} \mathrm{~N}_{\text {bulk }}$ and $\delta^{15} \mathrm{~N}_{\text {ker }}$ values imply that the enhancement of $\mathrm{N}_{2}$ fixation by cyanobacteria using molybdenum (Mo)-based nitrogenase enzyme played a critical role in keeping pace with bioavailable $\mathrm{N}$ loss following quantitative denitrification and/or anammox in a strongly redox-stratified marine setting. Such N isotope compositions are in contrast to the typical sedimentary $\delta^{15} \mathrm{~N}$ values (> $3 \%$ ) induced by partial water-column denitrification and/or anammox in oxygen minimum zones of the present-day ocean [3]. We propose the existence of local oxygendeficient niches on the northern European epicontinental shelf in which dissolved $\mathrm{N}$ pool underwent extensive denitrification and/or anammox resulting in bioavailable $\mathrm{N}$ scarcity. Mo-based diazotrophy thus played a critical role in discriminating $\mathrm{N}$ isotope compositions among multiple hydrographically restricted T-CIE marginal basins.

[1] Jenkyns (1988), American Journal of Science 288, 101151. [2] McArthur (2019), Chemical Geology 522, 71-83. [3] Stüeken et al. (2016), Earth-Science Reviews 160, 220-239. 